HISPANICA 39 (1995)

\title{
Verbos soporte con valor aspectual
}

Kazumi KOIKE

\section{Objetivo}

Este trabajo es la continuación de nuestros estudios precedentes (Koike 1992, 1993a, 1993b y 1994) sobre el verbo compuesto. De las siguientes tres estructuras principales del verbo compuesto que estableció Koike (1993a), este artículo trata de la segunda estructura: Verbo soporte (Vsop, en adelante) + Sin. tagma Preposicional (SP, en adelante).

I. Verbo compuesto nominal: Vsop + Sustantivo predicativo (tomar ladoptar, tener] precaución)

II. Verbo compuesto preposicional: Vsop + SP (andar [ir] con precaución)

III. Verbo compuesto adjetival: Vsop + Adjetivo (andar precavido)

En este artículo senalamos la existencia de un grupo de verbos compuestos preposicionales, como los que aparecen en (1) a (8), que indican el aspecto, analizamos sus características sintácticas y semánticas, y finalmente hacemos una clasificación basada en valores aspectuales de dichos verbos.

(1) Tan pronto como el comisario oyó las declaraciones del arrestado entró en duda de quién sería el culpable. (DP, s.v. entrar)

(2) Cuando vino en conocimiento de lo que había pasado, ya era demasiado tarde. (DP, s.v. venir)

(3) Nos caíamos de risa oyéndole. (DUE, s.v. caerse)

(4) Se muere de ganas de venir (de miedo, de vergüenza, de envidia). (DUE, s.v. morirse)

(5) ¿Estás de mudanza? - le preguntó el Cubano. (Torrente Ballester, II376)

(6) Me encuentro en la imposibilidad de ayudarle. (DUE, s.v. imposibilidad)

(7) Ándate con cuidado al cruzar la calle, no te coja un coche. (DP, s.v. 
coger)

(8) El abogado llegó a la persuasión de que su defendido es inocente. (NDEJ, s.v. persuasión)

\section{Tipos de predicación verbal y SP en función de predicado}

El núcleo del predicado verbal suele ser un verbo, y el verbo es capaz de formar por sí solo un predicado. Pero existen en español sustantivos y adjetivos que pueden formar el predicado verbal con un apoyo sintáctico. El verbo "acon. sejar" puede ser el núcleo del predicado, frente al sustantivo "consejo" que requiere el verbo funcional "dar" para desempeñar la misma función (“dar un con. sejo"). Lo mismo ocurre con el adjetivo "enfermo", que se convierte en el núcleo del predicado en la expresión "caer enfermo", cuyo equivalente verbal es el ver. bo "enfermar[se]".

Por otra parte, algunos sintagmas preposicionales pueden constituir el núcleo del predicado, lo mismo que el sustantivo y el adjetivo, con el apoyo sintáctico de algunos verbos funcionales a los que llamamos "verbos soporte". Los sintagmas preposicionales (subrayados) de los ejemplos (1) a (13) forman parte del núcleo verbal, puesto que el peso semántico está en los respectivos sustantivos que los componen y la selección de argumentos oracionales depende de ellos ("duda", "conocimiento", etc.), lo cual vamos a verificar detalladamente en el tercer apartado.

(9) Esta expresión ha caído en desuso ${ }^{(1)}$.

(10) Las prisas van en detrimento de la perfección. (NDEJ, s.v. detrimento)

(11) Es una de las muchas damiselas que andan a la caza de un buen par. tido. (DP, s.v. damisela)

(12) Entró en una explicación detallada de las virtudes, propiedades y buenos hábitos de las mulatas. (Torrente Ballester, III-31)

(13) Sebastián está a la espera de la concesión de una beca. (NDEJ, s.v. espera)

Al considerar la relación con las tres estructuras del verbo compuesto, existen en español los siguientes cinco tipos de expresiones verbales capaces de formar el predicado verbal:

A) Verbo simple denominal (aconsejar) 
B) Verbo compuesto nominal (dar un consejo)

C) Verbo compuesto preposicional (caer en desuso)

D) Verbo simple deadjetival (enfermar)

E) Verbo compuesto adjetival (caer enfermo) ${ }^{(2)}$

Parece poco frecuente que los vocablos de la misma raiz tengan todas estas posibilidades combinatorias. Los sustantivos "consejo" y "uso", por ejemplo, no tienen expresiones correspondientes a los tipos D) y E). El sustantivo "impunidad" y el adjetivo "impune" que carecen del verbo simple de la misma raíz tienen sus correspondientes expresiones verbales formadas por un Vsop: "quedar en la impunidad" (tipo C), "quedar impune" (tipo E). El sustantivo "desilusión" que tiene el verbo de la misma raíz "desilusionarse" (tipo A), puede convertirse en las expresiones verbales del tipo B ("llevarse [sufrir, tener] una desilusión") y del tipo C ("caer en la desilusión"). Existe también el tipo E: "estar desilusionado", aunque no tiene un verbo deadjetival en este caso.

\section{Verbo soporte y sus variantes}

El verbo simple es una forma sintética y el compuesto una forma analitica, pero son dos estructuras paralelas desde el punto de vista semántico, aunque hay diferencia de matices. El primero sólo admite una modificación adverbial por su carácter sintético, mientras que el segundo puede ser modificado por adjetivos por estar formado por un elemento verbal y otro sustantivo (viajar $\underline{\text { mucho }}$ - hacer un viaje magnífico).

La llamada perifrasis verbal concede a un verbo valores gramaticales como el modal, el temporal o el aspectual. Por otro lado el verbo compuesto preposicional indica, entre otros valores ${ }^{(3)}$, los aspectuales. Se puede observar en la pareja de la perifrasis verbal y el verbo compuesto preposicional el paralelismo que hay entre el verbo simple y el compuesto nominal. Vamos a ver un ejemplo. El sustantivo "broma" puede convertirse en un sintagma verbal al combinarse con determinados verbos soporte. Así se dice "gastar bromas", "andar con bromas", "estar de bromas" o "dejarse de bromas". El verbo "gastar" es el verbo soporte neutro y los verbos "andar", "estar" y "dejarse" son los verbos soporte con valor aspectual de duración ${ }^{(4)}$. Al verbo compuesto "gastar bromas" corres. ponde el verbo simple "bromear", el cual admite a su vez una modificacion 
aspectual mediante un verbo auxiliar, formando así una construcción perifrástica: "estar bromeando", "andar bromeando", etc. Las expresiones verbales "andar con bromas", "estar de bromas" y "dejarse de bromas", a los cuales llamamos verbos compuestos con valor aspectual, expresan significados simi. lares a los de las perifrasis verbales aspectuales "andar(se) bromeando", "estar bromeando" y "dejar de bromear", respectivamente.

\begin{tabular}{|ll|}
\hline $\begin{array}{ll}\text { Verbo simple } \\
\text { bromear }\end{array}$ & $\begin{array}{l}\text { Verbo compuesto nominal } \\
\text { Perífrasis verbal bromas }\end{array}$ \\
\hline $\begin{array}{l}\text { andar bromeando } \\
\text { estar bromeando }\end{array}$ & $\begin{array}{l}\text { Verbo compuesto preposicional } \\
\text { dejar de bromear }\end{array}$ \\
\hline
\end{tabular}

El sustantivo predicativo "broma", pues, dispone de inventario completo que llena esta estructura cuádruple. En cambio, como se puede ver en el esquema siguiente, el sustantivo "vigor" de "entrar en vigor" no dispone de eso:

ø entrar en vigor - la entrada en vigor de una ley estar [seguir] en vigor poner (una ley) en vigor - la puesta en vigor de una ley

El verbo compuesto "entrar en vigor", que indica un valor incoativo, no tiene un verbo simple morfológicamente asociado, ni un verbo compuesto neutro, aunque sí tiene un sustantivo compuesto "la entrada en vigor".

\section{Verbos soporte con valor aspectual}

\subsection{Características del verbo compuesto preposicional}

En este apartado estudiamos algunos rasgos que diferencian el verbo compuesto preposicional de otras expresiones formadas por un verbo y un SP de valor adverbial ${ }^{(5)}$. Los verbos compuestos preposicionales se caracterizan, como otros tipos de esta categoría del verbo, por presentar los siguientes rasgos:

a) El Vsop, carente del contenido propiamente léxico que le permita selec- 
cionar argumentos oracionales, indica los morfemas verbales del predicado (el tiempo, el modo, la persona y el número).

b) La posible ausencia o debilitamiento del valor adverbial del SP

\subsubsection{Sustantivo concreto y sustantivo predicativo}

Es evidente que los SSPP de (14) y (15) son de indole diferente, el uno es un complemento circunstancial del verbo "ir" y el otro un componente del verbo compuesto.

(14) Pedro va en coche.

(15) El alboroto va en aumento. (NDEJ, s.v. alboroto)

En (14) el verbo "ir" posee su contenido léxico pleno y exige el sujeto "Pedro" y el complemento circunstancial "en coche". En cambio, en (15) el sujeto gramatical "el alboroto", aunque concuerda con el Vsop "ir", no es seleccionado semánticamente por este verbo, sino por el sustantivo "aumento".

\subsubsection{Selección del sujeto y complemento}

El elemento que selecciona los argumentos del predicado, como acabamos de ver, no es el verbo, sino el sustantivo, lo cual puede comprobarse al comparar las frases sinónimas (16) y (16a).

(16) La falta de amabilidad de un empleado desacredita a toda la empresa. (NDEJ, s.v. desacreditar)

(16 a) La falta de amabilidad de un empleado va en descrédito de toda la empresa.

En (16) el verbo "desacreditar" exige semánticamente su sujeto gramatical ("la falta de amabilidad") y su complemento directo ("toda la empresa"), mientras que en (16a) es el sustantivo "descrédito" el que selecciona el sujeto y el com. plemento. Veamos más ejemplos. En (17) a (20) los complementos introducidos por una preposición no dependen semánticamente de sus respectivos verbos soporte ("estaba", "estamos", "vino" y "arde"), sino de los sustantivos correspondientes ("acecho", "preparativos", "conocimiento" y "deseos").

(17) El gato estaba al acecho del ratón.

(18) Estamos de preparativos de viaje. (DUE, s.v. estar)

(19) Cuando vino en conocimiento de lo que había pasado, ya era de- 
masiado tarde. (DP, s.v. venir)

(20) Arde en deseos de conocer la noticia. (DP, s.v. arder)

3.1.3. Mantenimiento de los argumentos

El número de argumentos se mantiene entre la construcción de un verbo simple y la de Vsop, aunque puede haber unos cambios sintácticos. En (16) y (16a) se conservan los argumentos "La falta de amabilidad..." y "toda la empresa". Los ejemplos (17) a (20) de construcción de Vsop también conservan el mismo número de argumentos del de los ejemplos siguientes:

(17a) El gato estaba acechando [acechabal al ratón. (NDEJ, s.v. acechar)

(18a) Estamos preparando el viaje. (DUE, s.v. estar)

(19a) Cuando conoció lo que habia pasado, ya era demasiado tarde.

(20a) Desea conocer la noticia.

3.1.4. Posible ausencia o debilitamiento del valor adverbial del SP

Mediante algunas transformaciones sintácticas pueden confirmarse el carácter auxiliar del Vsop y la posible ausencia o debilitamiento del valor adverbial del SP.

La frase (21), que es una construcción de un verbo con contenido léxico y un SP con valor adverbial, es desglosable en $(21 a)^{(6)}$, pero (22) no tolera tal disociación.

(21) Juan anda con la espalda encorvada.

(22) Juan siempre anda con bromas.

(21a) Cuando anda Juan, lo hace con la espalda encorvada.

(22a) *Cuando anda Juan, lo hace siempre con bromas.

La frase (21) podría ser una respuesta a la interrogativa con "cómo", mientras que la (22) no puede serlo.

(23) ¿Cómo anda Juan?

- Anda con la espalda encorvada. / Anda a grandes pasos.

- *Anda con bromas.

Para tener como respuesta la frase (21), es preciso formular la pregunta en la que aparece el verbo "hacer":

(24) ¿Qué anda haciendo Juan? 
- *Anda con la espalda encorvada.

- Anda con bromas.

Este comportamiento parece confirmar el carácter unitario de "andar con bromas" y, por lo tanto, el carácter no adverbial de "con bromas".

Veamos más ejemplos. El SP de la expresión "caer en desuso" no permite la enfatización mediante el relativo adverbial "como", "sino mediante el pronombre relativo "(en) lo que". El mismo comportamiento se observa en la tematización del SP "en duda" de "entrar en duda" y "en detrimento (de la perfección)" de "ir en detrimento (de la perfección)".

(25) En desuso es en lo que [*como / ?donde] cayó esta expresión.

(26) En duda es en lo que [ ${ }^{*}$ dondel entró el comisario.

(27) En detrimento de la perfección es en lo que ${ }^{*}$ comol van las prisas.

La posibilidad de tematizar el complemento del verbo compuesto "de la perfección", como puede observarse en (27a), viene en apoyo de que la expresión verbal "ir en detrimento" es una unidad autónoma en su conjunto.

(27a) De lo que las prisas van en detrimentos es de la perfección.

\subsubsection{Reducción a cero del Vsop}

Para comprobar la posible ausencia o debilitamiento ${ }^{(7)}$ del contenido propiamente léxico del Vsop, podemos utilizar el método de reducción a cero del soporte $^{(8)}$. Esta transformación sólo hace perder el valor aspectual que éste posee, pero no supone la pérdida total del contenido léxico que indicaba el verbo compuesto en conjunto.

Si prescindimos del valor aspectual expresado por el Vsop, podemos suprimirlo como puede comprobarse en (28a) y (29a).

(28) Una expresión ha caído en desuso.

(28a) Una expresión (caída) en desuso.

(29) Las nuevas normas entrarán en vigor el próximo mes. (DP, s.v. vigor)

(29a) Las nuevas normas, en vigor el próximo mes ${ }^{(9)}$.

A la construcción del verbo compuesto (30) puede aplicarse las operaciones (30a) (30b) y (30c):

(30) Juan anda en los trámites del divorcio.

(30a) Los trámites del divorcio en los que anda Juan. 
(30b) Los trámites del divorcio de Juan.

(30c) Juan, en los trámites del divorcio desde hace meses.

Pero la construcción de un verbo léxico (31) no tolera esta reducción a cero. Se pierde totalmente el contenido léxico expresado por el verbo "indignarse" en (31b) y (31c):

(31) Juan se indignó con los trámites del divorcio.

(31a) Los trámites del divorcio con los que se indignó Juan.

(31b) * Los trámites del divorcio de Juan.

(31c) *Juan, con los trámites del divorcio.

\subsubsection{Conmutación léxica}

La construcción del Vsop que nos ocupa en este artículo es una estructura capaz de producir nuevas expresiones verbales. Es decir, dispone de la posibilidad de sustitución del sustantivo por otro. La estructura "caer" es compatible con los sintagmas preposicionales como "en desuso", "en la desesperación", "en la desilusión", "en el olvido", etc. Esta conmutación léxica se efectúa en el verbo en forma no personal en el caso de la perífrasis verbal, que también es una estructura productiva y con la que algunos verbos soporte mantienen un paralelismo semántico ${ }^{(19)}$.

(32) Estamos de mudanza [preparativos de viaje]. (DUE, s.v. estar)

(33) Estamos mudándonos (preparando el viaje]. (DUE s.v. estar)

(34) Cuando ya no pudo más rompió a llorar estrepitosamente. (Gómez Torrego, 1988: 114)

(35) Cuando ya no pudo más rompió en llanto estrepitoso.

Por otro lado, la conmutación también es posible en el Vsop, puesto que la mayor parte de los sintagmas preposicionales son compatibles con más de un verbo: caer [estar, dejar...] en desuso, andar [estar] a la caza de, etc.

\subsubsection{Correspondencia léxica a un verbo simple}

Aunque hay verbos compuestos que carecen de una correspondencia léxica con un verbo simple, bastantes de ellos tienen un verbo simple de la misma raíz: caer [hundirse] en la desesperación - desesperarse / caer en la desilusión - desilu. sionarse / entrar en explicación - explicar / estar a la espera - esperar / estar al 
[en] acecho - acechar / andar con chismes-chismorrear / andar a la brega - bregar / andaba [estar, ir] de viaje - viajar / ir [redundar] en desdoro de - desdorar / llegar a la persuasión - persuadirse, etc.

(36) Los soldados que patrullaban el campamento observaron un movimiento anormal de tropas durante la noche. (DP, s.v. patrullar)

(36a) Los soldados que andaban de patrulla en el campamento observaron un movimiento anormal de tropas durante la noche.

La sustitución del verbo simple por el compuesto, como puede verse en (36) y (36a), es una operación aceptable, aunque puede producir cambios de estructura sintáctica (la aparición de preposición en este caso) y de matiz. Esta conmutación confirma el paralelismo entre verbo compuesto y verbo simple $\mathrm{y}$ viene a respaldar el estatuto que damos a la construcción del Vsop, es decir, el verbo compuesto.

La ausencia de verbo simple de la misma raíz en algunos verbos compuestos no contradice nuestra tesis, porque consideramos que se trata simplemente de un vacío del inventario léxico del español, el cual precisamente el verbo compuesto puede llenar.

\subsubsection{Flexibilidad formal}

Otra característica del verbo compuesto preposicional es admitir una modificación adjetiva por ser una forma analítica, frente al verbo simple que sólo admite una modificación adverbial ${ }^{(1)}$. Por ejemplo, al sustantivo "explicación" de "entrar en explicación" se le puede agregar el adjetivo "detallada" como puede observarse en (12) y al sustantivo "cautela", el adjetivo "mucha" ("andar con mucha cautela").

(12) Entró en una explicación detallada de las virtudes, propiedades y buenos hábitos de las mulatas. (Torrente Ballester, III-31)

\subsection{Verbos soporte con valor aspectual}

Desde el punto de vista sintáctico pueden distinguirse dos tipos de Vsop compatibles con un SP: uno es el verbo transitivo que forma el compuesto como "poner en marcha algo" y el otro el intransitivo o pronominal que forma parte de las expresiones del tipo "andarse con bromas", "romper en sollozos", etc. Los 
verbos compuestos que presentan valores aspectuales pertenecen al segundo grupo. Los valores aspectuales representados por estos verbos son similares a los expresados por las perifrasis verbales: el incoativo, el durativo, el terminativo, etc. A continuación vamos a exponer una lista de verbos soporte del segundo tipo que indican varios valores aspectuales. Hemos establecido cuatro grupos que indican el aspecto incoativo, el durativo-reiterativo, el intensificativo ${ }^{(12)}$ y el terminativo-resultativo, respectivamente. Esta clasificación no está basada en criterios estrictos, sino en una tendencia general observada en el corpus que manejamos, por lo que puede haber errores e imprecisiones.

\section{A) Aspecto incoativo}

Hay un grupo de verbos compuestos preposicionales que tienen como valor fundamental indicar el principio de una acción. En unos casos se indica la brusquedad del principio de una acción ("estallar en "), en otros se observa un valor ponderativo ("caer en la desesperación").

caer en el abatimiento (desuso, el pecado, la desesperación, la desilusión, la ignominia, la miseria, falta] / emprenderla a bofetadas [insultos, patadas] con alguien / entrar [meter] a saco / entrar en [conversaciones, duda, explicación, la cuestión, vigor] / estallar en llanto [sollozos] / montar en cólera [ira] / ponerse en [contacto con $\sim$, actitud de $\sim$ / prorrumpir en sollozos [exclamación, gritos] / romper en sollozos [llanto]

\section{B) Aspecto durativo-reiterativo}

Otro grupo expresa la acción durativa. Algunos verbos compuestos como "andar con" aporta "unos valores de tipo frecuentativo o reiterativo (repetición de actos) con la idea de un movimiento sin dirección fija" (Gómez Torrego 1988: 149).

andar a puñetazos (la brega, la briba, la caza] / andar con bromas [cautela, cuentos, chismes (chismorrear), miramientos, misterios, remilgos, rodeos, tapujos, precaución] / andar de cháchara [patrulla, viaje] / andar en cambalaches [conciliábulos, dares y tomares, dimes y diretes / andar en [con] chanchullo[s] 
[combinación, trajines, trapicheos] / continuar con la ayuda [broma] / encontrarse en necesidad de $\sim$ [la imposibilidad de $\sim$ ) / estar al servicio [(a)l mando, (a)l habla, la espera de $\sim$. la caza de $\sim$ / estar al [en] acecho / estar de bromas lacuerdo con $\sim$, cachondeo, campamento, centinela, malhumor, mudanza, charla, fiesta, guarnición, humor, preparativos de $\sim$, viaje, veraneol / estar de [en] obras / estar en desorden lactitud de $\sim$, espera de $\sim$, guerra, ignorancia, la imposibilidad de $\sim$, sintonía con $\sim$, comunicación, compañia, competencia, contacto, contradicción con $\sim$ / / ir de bajada [caída] / seguir con su trabajo / seguir en coma

C) Aspecto intensificativo

Los verbos que pertenecen a este grupo intensifican el contenido expresado por el sustantivo que forma el SP. Por ejempo, el Vsop "morirse de " de las siguientes frases indica un aspecto de intensidad ${ }^{(13)}$.

(37) Se muere de ganas de venir |miedo, vergüenza, envidia). (DUE, s.v. morirse)

El verbo "morirse" no significa aquí "perder la vida", sino que sólo intensifica el contenido léxico de los sustantivos introducidos por la preposición "de":

(37a) Tiene muchas ganas de venir [mucho miedo, mucha vergüenza, mucha envidial.

anegarse en llanto / arder en deseos de $\sim$ / bramar [mugir, rugir] de ira / encenderse en ira / deshacerse en alabanzas [cumplidos, atenciones con alguien, excusas, imprecaciones, lágrimas, suspiros, llanto, queja, suspiros, zalemas| / llenarse de ira / morirse de miedo /vergüenza, envidia, hambre, sed, risa, ganas de $\sim$, curiosidad por $\sim 1$

\section{D) Aspecto terminativo-resultativo}

Al cuarto grupo pertenecen los verbos compuestos que indican la acción verbal en su término.

dejarse de garambaina [bromas] / ir en descrédito de - laumento (aumentar), ayuda de $\sim$, desdoro de $\sim$, detrimento de $\sim$ I / llegar a un arreglo luna 
conclusión de (algo) / quedar en la impunidad [en ridiculo] / redundar en desdoro de $\sim$ |detrimento de $\sim$ l / resultar en detrimento de $\sim$ / venir en conocimiento de $\sim$ lapoyo de $\sim$, detrimento de $\sim l^{(14)}$

\section{Observación final}

Las características comprobadas hasta aqui confirman una posible existencia de verbos compuestos preposicionales que indican valores aspectuales. Esta categoría verbal tiene a su vez una estructura productiva como las de perifrasis verbales y de otras estructuras del verbo compuesto, aunque la descripción de la misma es todavía insuficiente.

Los verbos compuestos preposicionales forman parte de las expresiones verbales analíticas, que constituyen a su vez un polo paralelo a los verbos simples y a las perífrasis verbales. El valor neutral del verbo simple y los valores gramaticales de las perifrasis verbales se manifiestan de otra manera en los verbos compuestos. Por ello es necesario no sólo describir esta categoría verbal dentro del ámbito del verbo compuesto, sino hacerlo en relación con los verbos simples y las perifrasis verbales. El análisis externo tiene la misma importancia que el interno.

Me gustaria dejar en claro que el verbo compuesto preposicional estudiado en este trabajo no es una expresión fija, la cual presenta características sintácticas, semánticas y léxicas diferentes a las de esta categoría verbal. La locución verbal posee dos significados: uno primitivo y el otro idiomático, mientras que el verbo compuesto no tiene más que un significado, y la suma de los componentes (un Vsop y un SP) es deducible.

Aunque existen locuciones verbales que toleran alguna conmutación léxica (por ej. apear del burro (a alguien) - caer (se) [apearsel del burro), la mayor parte de ellas son las expresiones únicas. En cambio, la conmutación léxica que le garantiza una capacidad productiva al verbo compuesto es un fenómeno es. table.

En este trabajo nos hemos ocupado solamente de los verbos compuestos preposicionales que presentan valores aspectuales. Antes de terminar deseamos señalar la existencia de otro tipo de los compuestos preposicionales que indican valores diatéticos. Son los casos del compuesto "caer en el olvido", que implica 
un contenido pasivo ("ser olvidado"), o "llenar a alguien de desconsuelo" que expresa la causatividad ("causar desconsuelo a alguien"). De estos verbos compuestos pensamos tratar en otra ocasión.

\section{Notas}

* Este texto es una versión revisada de la ponencia presentada, con el titulo de "Verbos soporte con valor aspectual", al XL Congreso de la Asociación Japonesa de Hispanistas. que tuvo lugar en la Universidad de Sofía en octubre de 1994. Quisiera expresar mi agradecimiento al profesor Patricio Valdivieso, quien ha revisado el texto desde el punto de vista de un nativo para que mi español quede comprensible.

(1) Una expresión caída en desuso (DUE, s.v. desuso)

(2) Habría que admitir quizá un posible sexto tipo "Vsop. + SP formado por una preposición y un adjetivo" como "poner algo en claro", "poner de manifiesto" que hemos incluido provisionalmente en la segunda estructura del verbo compuesto.

(3) Hay verbos compuestos que expresan un valor diatético: caer en el olvido ( $=$ ser olvidado) (pasividad)

(4) Hay verbos compuestos adjetivales (Vsop + adjetivo) que indican valores aspectuales: "andar preocupado".

(5) Los métodos aplicados en este apartado se basan en los utilizados por Vivès (1993) y Gross (1989).

(6) Es un método utilizado por Gómez Torrego (1988: 127-129) para comprobar la ausencia de una perífrasis verbal de gerundio

(7) Porroche (1988: 20) habla de la pérdida del valor léxico originario del verbo "an. dar" de "él anda enamorado".

(8) Es la aplicación modificada del método utilizado por Gross (1989: 107-127).

(9) Cf. El Tratado sobre el Cambio Climático, en vigor sin que la UE tenga su 'ecotasa' (El Pais. Ed. Internacional, 28-03.94)

(10) Gómez Torrego (1988), al referirse a la perífrasis "romper a +inf.", dice lo siguiente: "(Los efectos estilisticos del auxiliar romper) Son valores que se mantienen en locu. ciones del tipo romper en llanto, romper en sollozos...". aunque piensa que "en estos casos romper es un verbo nuclear, y en la perifrasis es un verbo auxiliar".

(11) El mismo fenómeno se observa entre el verbo compuesto nominal y el verbo simple:

Pedro dio un consejo valioso a Marta.

Pedro aconsejó con acierto a Marta.

Lo mismo puede ocurrir también con la pareja del verbo compuesto preposicional y la perifrasis verbal. 
(12) Muraki (1991: 280) admite un aspecto intensificativo en algunos verbos funcionales japoneses.

(13) La acepción que da el DUE a "morirse de " es "experimentar violentamente lo que se dice a continuación".

(14) El Diccionario Planeta de la lengua española usual da la siguiente acepción al verbo "venir": "Seguido de la prep. en y un sustantivo, toma la significación del verbo corres. pondiente a dicho sustantivo"

\section{Fuentes de los ejemplos citados:}

DUE $=$ Moliner. Maria (1988): Diccionario de Uso del Español, Madrid (Gredos).

DP = Marsá, Francisco (1982): Diccionario Planeta de la lengua española usual, Barcelona (Planeta).

NDEJ = Ueda. Hiroto et al. (1992): Nuevo Diccionario Español-Japonés. Tokio (Kenkyusha).

Torrente Ballester, Gonzalo (1982): Los gozos y las sombras, I-III. Madrid (Alianza).

\section{Bibliografía de obras citadas}

Gómez Torrego, Leonardo (1988): Perifrasis verbales, Madrid (Arco Libros).

Gross, Gaston. (1989): Les constructions converses du français, Genève (Droz).

Koike, Kazumi (1992): "Locución verbal y verbo compuesto", Hispánica, 36. Tokio (Asociación Japonesa de Hispanistas), 89-104.

-(1993a), "Caracterización y estructuras del verbo compuesto". Hispanica 37, Tokio (Asociación Japonesa de Hispanistas). 14-29.

- (1993b), "ddar" como verbo soporte". Actas del III Congreso de la Asociación Asia. tica de Hispanistas. Tokio. (AAH). 216-225.

- (1994), "Construcciones del verbo soporte "andar + sintagma preposicional"". Ver. bo e estruturas frásicas. Actas do IV Colóquio Internacional de Linguistica Hispánica. 299-310. Porto: Univ. do Porto.

Muraki, Shinjiro (1991), Aspectos de verbos japoneses (en japonés), Tokio: Hitusji-Shobo.

Porroche Ballesteros. Margarita (1988): Ser, estar y verbos de cambio, Madrid (Arco Li. bros).

Vivès, Robert (1993), "La prédication nominale et l'analyse par verbes supports". L'in. formation grammaticale, N59. 8-15. 